\title{
¿Qué hacer con nuestro modelo neo-liberal, con tan poca entropía? Chile vs. Corea: asimetrías productivas y distributivas.
}

\author{
José Gabriel Palma *
}

UNIVERSIDAD DE CAMBRIDGE Y UNIVERSIDAD DE SANTIAGO DE CHILE

\section{RESUMEN}

Este artículo explica la forma en que se comporta la economía chilena en relación a Corea, que crece más y reparte mejor las ganancias. Analiza cómo en Chile el sistema parece diseñado para beneficiar a un fracción mínima de la población (particularmente al empresariado). En el presente crece el descontento por la acumulación de riqueza en manos de unos pocos y Palma se pregunta si Chile (gobierno y empresarios) ha pensado una solución.

Palabras Claves: Chile, Corea, riqueza, acumulación, distribución

\begin{abstract}
This article explains how the Chilean economy behaves in relation to Korea, which grows more and better dividends. It analyzes how in Chile the system seems designed to benefit a small fraction of the population (particularly the entrepreneurs). In the present grows discontent over the accumulation of wealth in the hands of a few and Palma wonders if Chile (government and businessmen) has thought a solution.
\end{abstract}

Keywords: Chile, Korea, wealth, accumulation, distribution

*jgp5@cam.ac.uk 
.- ¿Cómo se puede justificar que en Chile el i\% MÁS RICO SE APROPIE DE LA TERCERA PARTE DEL INGRESO 1 nacional? Empresarios chilenos vs. Coreanos

Desde mi perspectiva analítica la pregunta fundamental a la base de nuestra fragilidad económica actual es ¡cómo puede ser posible que en una economía como la chilena el 1\% más rico se apropie de alrededor de la tercera parte del ingreso, y cómo puede ser que ese $1 \%$ crea (ilusoriamente) que eso es sustentable en el tiempo, a pesar de los costos crecientes asociados con eso para el resto del país en términos de ineficiencia productiva, desigualdad e injusticia social? ${ }^{1}$ No olvidemos que en economías con bastante más dinamismo, como la coreana y la taiwanesa, sus homólogos se llevan apenas un tercio de eso $(11 \%$ o $12 \%) .{ }^{2}$ ¿Cuál podría ser la lógica de tamaño contraste? Sin duda muchas otras oligarquías en el mundo (incluso en Asia) quisieran ganar en las dimensiones chilenas, pero las coordenadas son otras.

El caso de Corea es particularmente relevante ya que hasta no hace tanto (años 80) teníamos niveles de productividad promedio por trabajador muy similares. Si comparamos todo el período neoliberal chileno (42 ańos), mientras nosotros sextuplicábamos el PIB, Corea, creciendo a una de las tasas más altas de mundo, lo multiplicó por $16 .{ }^{3}$ Y si comparamos desde 1980 , cuando ambas economías tenían niveles similares de desarrollo (hacia fines del período de las reformas lideradas por los duros de los Chicago-Boys, aquellos yihadistas que confundían arrogancia con conocimiento), mientras Corea crece durante este período de 35 años a una velocidad casi sin paralelos, nuestro país sólo está en el lugar 23 de la tabla de posiciones. Incluso durante nuestros años más dinámicos (19861998) ambas economías crecieron a tasas similares; la diferencia fue que a ellos, Corea, no se les acabó el oxígeno después de eso, como a nosotros, ni siquiera con su crisis del ' 97 - el contraste entre ser corredores de maratón y sólo de media distancia.

Entonces, ¿por qué la elite capitalista coreana se premia con tan poco por lograr tanto, mientras que nuestra oligarquía se lleva tres veces más de la torta a pesar de su falta de dinamismo?

Como decíamos, en 1980 las productividades medias en ambos países eran similares, y estaban en alrededor de un quinto de Estados 
Unidos (Chile 21\% y Corea 19\%). En esa época, Corea ya había cerrado su brecha productiva con nosotros, pues cuando comenzó a industrializarse en los ' 60 su productividad promedio era apenas la mitad de la nuestra.

En los 34 años siguientes (1980-2014), mientras nosotros apenas cerrábamos la brecha con EE.UU. en algo minúsculo (2 puntos porcentuales, llegando al 23\%), Corea logró avanzar 15 veces más, llegando a la mitad de la del país del norte (si usamos en cambio dólares PPP, la situación no es diferente, pues nosotros cerramos la brecha en tan sólo 3,7 puntos porcentuales). De seguir a estas velocidades, Corea se demoraría 60 años en cerrar totalmente su brecha productiva con EE.UU., mientras nosotros necesitaríamos más de un milenio.

Pregunta: ¿no deberían ser las recompensas para el $1 \%$ en ambos países al revés, con el $1 \%$ chileno premiándose con mucho menos que el coreano y no con tres veces más?

La diferencia es incluso más notable si se compara lo que se apropia en ambos países el $0,1 \%$ de los más altos ingresos: mientras en Chile esa pequeña minoría se cree con el derecho divino de llevarse un $20 \%$ del ingreso nacional (hasta un $22 \%$ en el 2008), en Corea ellos se conforman con 5 veces menos $(4,4 \%)$. El contraste con lo que se apropia el $0,01 \%$, compuesto en Chile por alrededor de unas 300 familias, ya llega al extremo pues en nuestro país ese grupo ínfimo acarrea con un $11,5 \%$ del ingreso total del país $(13,6$ en el 2008), mientras que en Corea ese grupo - quizás los empresarios más exitosos del mundo - se quedan satisfechos con un séptimo de eso $(1,7 \%)$.

Al margen de los inevitables (y en casos insolubles) problemas de medición y comparación entre países, ¿cuál podría ser la lógica de ese contraste alucinante - otra que ser una falla teutónica de mercado, la cual estaría a la base de los crecientes problemas económicos de nuestro país?

¿Cuál podría ser la racionalidad que lleva a la familia Samsung a llevarse para la casa (en términos genéricos) una retribución relativa 7 veces menor que la de sus homólogos chilenos, a pesar de ser capaz de competir mano a mano con Apple en electrónica, con Intel por el chip más rápido del mundo, y de tener junto a LG el dominio 
absoluto del mercado mundial de pantallas planas (y gracias a sus tecnologías avanzadas, no por colusión)? Mientras tanto, algunos de sus análogos chilenos se llevan tantas veces más por hacer cosas tan básicas como concentrado de cobre - un barro con un contenido de metal de aproximadamente un $30 \%$, resultado de una flotación rudimentaria del mineral bruto pulverizado.

¿O cuál podría ser la lógica que hace ser a los Hyundai tan pudoroso mientras construye autos con tecnologías de punta? Sus homólogos chilenos, mientras tanto, se llevan algo sideralmente mayor tan sólo por hacer astilla de madera y pulpa para diarios. ¿Y por qué los dueños de astilleros de barcos en Corea, como los Daewoo, son igual de recatados mientras construyen los barcos más grandes, complejos y tecnológicamente avanzados de la historia? ${ }^{4}$ Los criollos, en cambio, exigen tantos múltiplos más para ellos por producir salmones de 3 kilos, con sus correspondientes piojos y extra dosis de antibióticos. Y el que se dedica a la pesca (literalmente) se ríe de los peces de colores, pues en Chile si una familia califica dentro de esas 300 , se puede llevar gratis cuotas pesqueras a perpetuidad, y con el aplauso cerrado de la barra brava neo-liberal de la Concertación (bueno, unas cuantas propinas ayudan).

¿Será que todas estas fallas sísmicas de mercado son el simple resultado que a tanto chileno se le olvidó lo que era la vergüenza, aquella emoción que antaño nos recordaba que éramos humanos? Cómo nos recuerda Jorge Bergoglio, la corrupción de todo tipo (incluida la ideológica) es una droga que produce dependencia.

El contraste es notable; mientras al empresario coreano se lleva tan poco por invertir tanto, desarrollar tanta tecnología y hacer cosas tan majestuosas, el autóctono del supermercado se siente merecedor de la tajada del león a pesar de ser incapaz de tener siquiera leche fresca entre sus productos (demasiado esfuerzo). El mismo empresario que para poder subir márgenes a esos niveles cósmicos tiene que echarle a perder el paladar a sus consumidores - $y$ venderles frutas y verduras con gusto a cartón, pero a precio de las mejores del mundo - en un país donde sí se puede producir las mejores del mundo.

De igual forma, ¿por qué será que un dueño de banco coreano exige márgenes tanto menores por contribuir al gran desarrollo industrial de su país, a diferencia del nuestro que no sabe qué hacer 
con toda la plata que gana prestando a tasas muchas veces usureras, a clientes a veces cautivos y en algunos casos con el aval del Estado? Y para que hablar de los desafortunos de Aguas Andinas y Alto Maipo, o de las ganancias fáciles de Aguas de Antofagasta (concesiones transables, tan legales como absurdas). $\mathrm{O}$ de las extraordinarios diferencias en ambos países en calidad y precio del Internet.

¿Y por qué será que en Corea empresarios coreanos compiten con el sector público por quien contribuye más a crear uno de los mejores sistemas educativos del mundo a todo nivel y no sólo para la elite? Y eso en un país donde al comenzar su proceso de industrialización en los '60, casi un tercio de la población era analfabeta.

¿Y por qué será que Corea gasta 11 veces más que nosotros (como porcentaje del PIB) en investigación y desarrollo, gasto que en parte fundamental hace el sector privado? En Chile quizás esa insignificancia basta y sobra para las cosas a las que se dedican nuestros grupos económicos.

Hay que preguntarse una y otra vez a qué se deberá que tantos de nuestros grandes empresarios se sienten con derecho a tanto, a cambio de tan poco esfuerzo tecnológico, por tan poca imaginación productiva y por tan mínima diversificación de nuestra economía. Y por qué en Chile pueden salirse con la suya. Dado nuestro ingreso por habitante, Chile es una de las economías menos diversificadas del mundo. Como dicen en inglés, ¿̇por qué se sentirán con derecho divino a tanto, por tan sólo recolectar la fruta que está al alcance de la mano?

¿Tendrá todo lo anterior algo que ver con que Corea (junto a Taiwán) -con su esfuerzo, imaginación, capacidad para tomar riesgos, sentido común en la tajada del gran capital y su relación con eficiencia productiva- tengan, junto a su asombroso éxito económico, la mejor distribución del ingreso "mercado" del mundo? (aquella antes de impuestos y transferencias). Una que es mucho más equitativa que la de cualquier país de la Unión Europea -Alemania incluida- o de los famosos países nórdicos, célebres por su equidad. Sólo un reducido grupo de ex-países comunistas (se cuentan con los dedos de una mano) todavía le hacen pelea. ¿Nosotros? Ranking 120 en esa variable y después de cinco gobiernos de la así llamada "centro-izquierda". 
Y desde el punto de vista de la distribución después de impuestos y transferencias, el "Coeficiente Palma" 5 nos indica que el 10\% más rico de nuestro país se lleva aproximadamente 3 veces más que el $40 \%$ más pobre; en Corea, este coeficiente es 1,1 . Esto es, mientras en Corea el $10 \%$ más rico se lleva prácticamente lo mismo que el $40 \%$ más pobre, en Chile pone el grito en el cielo si no está alrededor de 3 veces sobre eso (la OECD entrega dos estimaciones diferentes para el "Palma ratio" de Chile, una arriba y una abajo del 3). ${ }^{6}$

Lo que queda claro es que incluso dentro del capitalismo hay formas muy distintas de hacer las cosas. Una con eficiencia, mayor equidad, empresarios schumpeterianos y un Estado capaz de disciplinar al gran capital y de darles derechos muy bien definidos a los medianos y pequeños productores. En Corea, por ejemplo, para poder instalar un supermercado había primero que compensar a los almacenes del barrio que iba a afectar (¡qué poca modernidad la de estos coreanos!). En tanto en Japón, una de las primeras medidas de la política industrial de la posguerra fue que nadie podía demorarse más de 90 días en pagarle a un proveedor.

La otra forma de hacer las cosas dentro del capitalismo es la que tenemos a la vista y presencia en nuestro país. Aquella en la que los del $1 \%$ pueden ganar tanto por tan poco esfuerzo productivo (con tan pocos desafíos productivos). En eso, la apropiación privada de la renta de los recursos naturales juega un rol fundamental, y recordemos que aún en nuestra Constitución, que por muy ilegítima y tramposa que sea es aún la que nos rige, y es la que Andrónico apoya, los dueños de esos recursos somos todos los chilenos. Bueno, como sabemos, en Chile esa afirmación no vale ni el papel en el que está escrito. A eso se suma la gran variedad de fallas de mercado (como la increíble falta de competencia entre los grandes), y la variedad y bien imaginativa gama de distorsiones - muchas hechas artificialmente a la medida, como la facilidad con que los grandes pueden estrujar a los medianos y chicos, y el tener un Estado "subsidiario" (aquél que se debería llamar así porque su rol fundamental es "subsidia que te subsidia" al gran capital).

Por eso digo que a los economistas que inventaron y justificaron esta segunda forma de hacer el capitalismo, en lugar de llamarse ingenieros comerciales, se deberían llamar ingenieros de sistema 
(otros, menos generosos, quizás los llamarían sastres que hacen buenos trajes a la medida, incluidos para ellos).

Que haya países donde las cosas están aún peor, es sólo el consuelo del mal de muchos...

2.- ¿Será QUe nUESTro i\% SE lleva tanto “por Ser los MEJORES”? ¿O PORQUE EL TRAJE ESTA HECHO A LA MEDIDA?

Quizás nuestra elite capitalista malentendió a Darwin, y cree que lo que él decía era que el que sobresalía era necesariamente "el mejor". Sí, sin duda en este modelo el 1\% más rico en Chile ha sobresalido con lujuria, pero para el ex-Cambridge "el más fuerte", o "el con más habilidades para sobrevivir y sobresalir" nunca tuvo una connotación valórica; "el mejor”. Esa calificación siempre se la han dado los que por cualquier razón están arriba - y su inevitable enjambre de aduladores - para justificar sus excesos. Para Darwin, dado un medio ambiente específico, sobresalen aquellos que tienen las habilidades y energías específicas relevantes. Cambie el medioambiente y el cuento es otro y el resultado puede ser uno muy distinto.

Daré un ejemplo personal. Si me ponen en un medioambiente académico típico, no me es tan complicado sobrevivir; pero cuando un día por despistado tuve que pasar casi toda una noche solo en la selva cerca de Tical, mis habilidades y conocimientos eran, literalmente, los más inútiles y mi capacidad de sobrevivencia nula (el que me encontró hizo un solo comentario respecto a mi torpeza en ese medioambiente: ¡hombre blanco tenía que ser!).

En otras palabras, si cambiamos el medioambiente $y$ transformamos nuestro capitalismo de segunda división en uno de primera, competitivo, con un Estado que respete la propiedad social de los recursos naturales (por ejemplo, colocando un royalty de verdad), y que le imponga un dinamismo y diversificación productiva asiático a la economía, lo más probable es que el $1 \%$ en Chile termine llevándose sólo algo cercano al 10\% del ingreso. Eso sucedía en EE.UU. antes de Reagan, y en el Reino Unido era incluso bastante menos que eso antes de la Thatcher. Y alrededor de eso es lo que se lleva hoy día el 1\% en Corea (12\%), Taiwán (11\%), o Alemania (13\%), mientras que en Dinamarca es aún menos. 
Además, no es muy claro cuántos de los actuales grupos económicos del país sobrevivirían en un mundo realmente competitivo y civilizado. Y para qué decir en uno en el cual la política industrial o comercial los llevase a tener que sobrevivir produciendo en Chile (vía controles a la salida de capital, como en tantos países asiáticos) e industrializando lo puramente extractivo, y sin poder apropiarse de gratis de las rentas de los recursos naturales, y con respeto a la naturaleza y al bienestar de los consumidores.

Por eso, uno de mis intentos por descifrar lo que es el neoliberalismo analiza su especificidad desde este punto de vista: es una ideología y una praxis político-económica e institucional que intenta crear, en forma totalmente artificial, un medioambiente a la medida de las habilidades y singularidades de un tipo específico de gran capital. Un medioambiente que le dé todas las ventajas para sobresalir al capital rentista, al financiero-especulador, a los trader, los depredadores, y todo aquél que se esconde de la competencia internacional operando en el sector de no-transables de bajo desafío tecnológico.

Pero ese medioambiente le hace la vida difícil a muchos, especialmente al capital realmente productivo, en especial el de la manufactura; aquél que vive en un mundo realmente competitivo, donde hay que trabajar mucho e innovar constantemente para poder ganar al menos un poco... En el Brasil pre-neoliberal, por ejemplo, la manufactura representaba mas del 30\% del PIB; hoy es menos del 10\%. ¿Tendrá eso algo que ver con su desastre económico actual? Pero, ¿cuál sería el problema si según el último informe Forbes en ese país el número de nuevos millonarios (con más de US $\$ 30$ millones en activos netos sin contar su residencia principal) centa-millonarios, o billonarios creció en 273\%, 274\% y 256\%, respectivamente desde que el "Partido de los Trabajadores" (!) tomó el gobierno? Y la inversión por trabajador en todo el período neoliberal (PT y boom de los commodities incluidos) fue menor que la que había en Brasil en 1980. De hecho, en 2013, con la economía ya entrando en crisis, en Brasil surgía un nuevo millonario de este tipo cada 27 minutos. Aun así, en Brasil su 1\% se lleva menos que el chileno (29\%). ${ }^{7}$

Básicamente, lo que hemos hecho en Chile no es más que crear 
una entelequia (primero a la fuerza y con abierta corrupción, y luego con la colaboración de los renovados y su "tercera vía”) que permita al 1\% llevarse para la casa un tercio del ingreso nacional con un mínimo de esfuerzo. Desde este punto de vista, la complejidad de lo real se puede sintetizar así: en la (auto-construida) selva neo-liberal, el capital (de ese tipo) es rey e increíblemente móvil. Si alguien todavía cree que la teología matemática, esa que hoy en muchas partes pasa por "ciencias económicas", tiene alguna evidencia empírica o teórica de verdad para apoyar eso desde el punto de la eficiencia, debería estudiar un poquito más el Asia, aquellos que por su envidiable pragmatismo ideológico son los eternos herejes del neo-liberalismo.

\section{3.- La genialidad de Roosevelt y Keynes vs. LA} MEDIOCRIDAD NEO-LIBERAL POSTERIOR.

Es importante recordar (en especial en tiempos donde la memoria es tan corta) que también hubo otro medioambiente capitalista diferente al neo-liberal, donde los "ganadores" eran otros: el sector productivo y los trabajadores - el cual FDR y Keynes ayudaron a crear en forma igualmente artificial. En aquél contexto, el espacio de maniobra del gran capital era muy claro y preciso: para el capital del sector real, si quieres hacer plata, ningún problema, pero tienes que hacer algo socialmente útil, ¡y en tu país! Para el sector financiero, como decía Keynes, su labor era generar crédito, y sólo en la medida que fuese "el pavimento a lo largo del cual pudiese viajar el sector productivo; y los banqueros, de saber su deber, sólo deberian proporcionar esos medios de transporte en la medida en la cual el sector productivo pueda generar pleno empleo". Para luego ańadir: "y que las finanzas sean primordialmente nacionales". Para el trabajo: ustedes tienen el derecho de propiedad de recibir una proporción adecuada del progreso económico que ustedes mismos ayudan a generar; tanto así, que en EE.UU. el ingreso del $40 \%$ más pobre creció más rápido que el del 1\% más rico hasta Reagan (y también más rápido que el ingreso del 0,1\% y el 0,01\%). En cambio, desde entonces (19792014), el ingreso promedio del $40 \%$ ha caído, mientras que el del $1 \%$ prácticamente se duplicó, el del $0,1 \%$ más que se triplicó, y el del 0,01\% más que se quintuplicó. De república bananera. 
Mientras tanto, en el período keynesiano las economías industrializadas crecían tanto en producto como en productividad a tasas jamás antes logradas, o después sustentadas; esto con pleno empleo y baja inflación. Y el CEO de Goldman Sachs no tenía la patudez de decir (como ahora) que su trabajo era equivalente "a hacer la misión de Dios en la tierra” (probablemente eso justificaría su remuneración celestial). Por su parte, las contribuciones corporativas a los fondos de pensión de los 100 CEO de las corporaciones más grandes de EE.UU. tampoco equivalían al stock de ahorros de pensión de 116 millones de sus compatriotas, como ocurre ahora. ${ }^{8}$

Pero claro, nuestro desafío no es resucitar ese pasado irreplicable, o copiar mecánicamente experiencias asiáticas (usar mecánicamente información de un pasado casi siempre irreplicable es el pecado original de la econometría). Pero sí hay que dejar de lado ese cuento neo-liberal criollo que, a pesar de toda la evidencia disponible, insiste en decir que hay una sola forma de hacer las cosas, la nuestra, y que por "puro mérito" ella beneficia tanto a tan pocos. Como dice la canción, eso es "teatro, puro teatro... falsedad bien ensayada, estudiado simulacro... fue tu mejor actuación... (pero) perdona que ya no te crea, pues (a estas alturas ya es bastante obvio que) lo tuyo es puro teatro".?

También hay que dejar atrás la amnesia neo-liberal que prefiere olvidar que en ese pasado el $1 \%$ más rico en EE.UU. ganaba menos de la mitad de lo que gana ahora como proporción del ingreso, proporción que incluso caía en el tiempo. De Reagan, Thatcher y la caída del Muro de Berlín en adelante, en cambio, cuando el poder del capital de ese tipo (sub-prime) se re-legitima en forma casi mítica, y los proyectos alternativos se desintegran, surge este nuevo modelo: un paraíso para los especuladores, rentistas, traders y depredadores, gracias al cual esa proporción se pegó un salto mortal hasta el momento de estallar la crisis financiera del 2007/8 - y ya está casi de vueltas a esas alturas siderales. ${ }^{10}$

No sólo este numerito fue un traje hecho a la medida, sino que terminó siendo un componente central de dicha crisis. ${ }^{11}$

Ahora lo que se lleva el $1 \%$ no sólo ya está casi de vuelta a esa tomadura de pelo, sino que también lo hace con una fragilidad financiera internacional peor que la anterior, y con gobiernos $y$ 
bancos centrales que ya se gastaron no sólo toda su pólvora, sino también su imaginación.

Probablemente gracias a su sabiduría milenaria (y errores del pasado) mucho de Asia se salvó de ese fundamentalismo, pues mientras todo occidente (norte y sur, en especial el mundo angloibérico) se tragaba la píldora de que esa ficción era la obra de Dumbledore, ellos sabían instintivamente que si venía de donde venía, sólo podía ser una construcción de Voldemort.

Básicamente, si hoy EE.UU. tuviese el mismo PIB, pero la distribución del ingreso fuese la misma que tenía cuando ganó Reagan (fruto del "momento Trump" de su época, cuando las fuerzas progresistas de entonces eran igualmente incapaz de ofrecer una alternativa viable y creíble para los descontentos de entonces), el 1\% más rico ganaría hoy día harto menos: más de 2 billones (millones de millones) de dólares menos de lo que gana ahora. Esa cantidad es equivalente a casi 10 PIB chilenos (dependiendo del tipo de cambio que se use). Y el resto de la población ganaría esa cantidad por sobre lo poco que le queda (y podría tener menos problemas para pagar por su vivienda, salud, educción, pensión, etc.).

En otras palabras, el 1\% más rico en los EE.UU. capturó más de dos tercios del crecimiento total de los ingresos reales por familia durante los últimos 20 años. ${ }^{12}$ Por su parte, el decil más alto llegó a llevarse más de la mitad del total de los ingresos del país, un nivel mayor al de cualquier otro año desde 1917, superando incluso a 1928 , año tope de la burbuja del mercado de valores de los "roaring $1920 "{ }^{13}$

¿Alguien (sin demasiados conflictos de interés) puede realmente creer que eso no es algo artificialmente construido para dicho fin, a costos crecientes desde el punto de vista de la eficiencia? Así, hoy tenemos el absurdo de una economía norteamericana casi estancada, pero con un sector corporativo cuyas utilidades están en record histórico y también con un nivel de deuda en record histórico. Lo mismo ocurre con la inversión privada, pero en el otro sentido (casi un record por lo bajo). Hay que dar reconocimiento donde ellos se merecen: la imaginación neo-liberal para crear artificialmente un medioambiente con esa esquizofrenia, de que se puede ganar tanto con tan poco esfuerzo - 
y en democracia - es realmente admirable.

Ese ha sido siempre el drama del capitalismo: su gran motor para desarrollar las fuerzas productivas viene sólo de la competencia, pero en mercados competitivos se trabaja mucho y se gana poco. En los mercados oligopólicos, desregulados y depredadores, en cambio, se puede ganar mucho trabajando poco - pero a gran costo en términos de eficiencia, equidad y medioambiente.

Esa tensión (muy bien predicha por Adam Smith) ha sido central en los 300 ańos de historia capitalista. Los Chicago (me refiero a los de verdad, no a los sacristanes criollos) tenían eso muy claro, y siempre estaban al lado de los mercados oligopólicos con el argumento de que mercados que requieren grandes niveles de inversión tienen que dar mínimas garantías de retorno al capital; y si hay demasiada competencia, eso no sucede. Sin embargo, no sólo al argumentar esto minimizaban el enorme costo de la concentración económica, sino también se olvidaban del problema de los incentivos: una vez que los mercados están tan concentrados y desregulados, ¿quién o qué los va a obligar a invertir?

4.- LA ARROGANCIA DEL PODER ABSOLUTO, Y LA RESIGNACIÓN DE LOS RENOVADOS.

El error garrafal de esta forma de acumulación y dominación fue su ilusión (bordeando en lo psicótico) de que este modelo era sustentable en el tiempo. Después de todo creían que habían logrado construir algo tan maravilloso que era nada menos que el fin de la historia.

Nuestra elite capitalista cometió el mismo error elemental; incluso logró acumular aún más, pero se hizo incapaz de adaptarse al cambio. En su voracidad se hizo incapaz de transformarse en el tiempo, algo esencial para hacer eso más sustentable. Va a quedar grabado en la historia política de Chile que uno de los errores históricos más garrafales de la oligarquía nacional fue rechazar la oferta de este gobierno: hagamos reformas mínimas para que todo pueda seguir casi igual (pero sin algunas de sus peores aristas). La miopía de la codicia y la arrogancia oligárquica pudo más. Si este gobierno hasta les ofreció aprobar el vergonzoso Tratado del Transpacífico (TPP), cuyo objetivo real era generar 
el mejor hedge posible contra el cambio, y el ceder soberanía político-económica de gratis a cortes Mickey Mouse, a niveles que hubiesen sido impensables en toda nuestra historia política nacional - al menos desde que Aníbal Pinto autorizó a Diego Barros Arana a ceder tanto cuanto fuese necesario de la Patagonia con tal que Argentina no apoyase a Perú y Bolivia en la Guerra del Pacífico. ${ }^{14}$ Dudo que esta oportunidad abierta por el gobierno actual se repita, pues a la collera ya se les arrancó el novillo.

Lo que es difícil de comprender no es por qué este ciclo políticoeconómico comienza a desintegrarse, sino cómo duró tanto tiempo. Sin tener el espacio necesario para analizar esto como se merece, creo que Freud nos da una buena pista (cosa que pasa a menudo). En un artículo escrito en medio de la Primera Guerra Mundial describe lo que considera ser las tres características básicas de los seres humanos cuando actúan ya sea como individuos o como grupo, en cuanto a su capacidad para comprender y actuar sobre el mundo real: a) su ambivalencia con la realidad relacionada con un miedo a lo desconocido, un temor al retorno a un caos primitivo donde puede existir una fuerza desconocida que destruya la comprensión y elimine el significado; la sensación es que puede existir un peligro real de que lo que por el momento es incomprendido terminará convirtiéndose para siempre en incomprensible. b) Su predilección por las ilusiones (y los cuentos de tanto cuanta-cuentos). Y c) su agresión innata. En lo ideológico, la genialidad de la "nueva izquierda" fue jugar con lo primero para contener el cambio, y con lo segundo para justificar su inacción (la "Tercera Vía” fue parte del cuento).

Desde este punto de vista, los renovados cumplieron con su rol de contención; el que falló fue su collera y por eso se les arrancó el novillo. Si la oligarquía tan solo hubiese entendido a Darwin: "El que sobresale no es el más fuerte, ni siquiera el más inteligente, sino el que mejor se adapta al cambio".

Pero claro, adaptarse al cambio en un modelo como el chileno era difícil. ¿De cuántas maneras se puede crear un medioambiente tan peculiar? Con mercados financieros todopoderosos, mercados laborales tan "flexibles"; falta de competencia a niveles antes impensables; sistemas de pensiones tan lucrativos para tantos, excepto para los pensionados; seguros privados de salud tan insalubres; un 
capital extranjero que pudo remitir al exterior utilidades equivalente a prácticamente un PIB entero entre 2002 y 2014 (y en su mayor parte por incomodarse en hacer cobre concentrado); estados tan eunucos que entre otras cosas podían seguir facilitando la apropiación privada indebida de la renta de los recursos naturales (minería, agua, pesca y más; el verdadero robo del siglo, pues legal o no, eso es lo que es). Un Estado tan esterilizado que no es capaz siquiera de obligar a los que se han adjudicado las concesiones de caminos a armonizar sus cobros vía un tag nacional. Algo para el Guiness Book of Records, sección costos sociales inútiles (tiempo inútilmente perdido en peajes).

\section{5.- El problema de modelos con baja entropía: como} TODO ORDEN SIEMPRE TIENDE AL DESORDEN, LAS FORMAS DE DOMINACIÓN DEBEN SOFISTICARSE CONSTANTEMENTE. ¿ES POSIBLE HACER ESO EN ESTE MODELO?

Desde esta perspectiva la pregunta es obvia: ¿de cuántas formas se puede adaptar algo así para que el $1 \%$ pueda seguir llevándose un tercio del ingreso año a año? Como diría un estadístico: ¿cuántos grados de libertad puede haber en un modelo así dado su rigidez intrínseca? O como diría un físico: ¿de cuántas formas se puede construir una estructura tan específica, con tan poca entropía? ¿De cuántas formas se puede crear algo tan bondadoso para algunos, al margen de su ineficiencia intrínseca, y en democracia? ¿De cuántas formas se puede construir algo así para limitar el acceso de otros a las rentas, construyendo tan efectivamente lo que Douglass Nor llamaba un "Limited Access Order"? ¿'De cuántas formas se puede re-arreglar los componentes de un modelo así sin cambiar su estructura ( $\sin$ desordenarlo)?

Si hay algo que es transparente en el Chile de hoy es que este tipo de dominación y acumulación se desintegra (y no sólo aquí). Pero ni la derecha ni la "nueva izquierda" han aportado una sola idea original - que sea creíble y viable - que ayude a hacer esto sustentable, algo no tan extraño en el caso de los últimos, pues cuando dos polos opuestos piensan lo mismo, en realidad sólo uno es el que está pensando. Por un lado, la "nueva izquierda" representa cada día menos a los descontentos, lo que es un componente esencial 
del tipo de dominación tan efectiva que nos trajo hasta aquí. Como ya he mencionado en otras columnas, citando a Adorno, Chile es laboratorio de eso de que la forma más efectiva de dominación es aquella que delega a los representantes de los dominados la violencia en la que descansa. Por otro, cada día es más obvio que la derecha no puede dominar efectivamente sin la ayuda de los renovados: ¿qué van a hacer las AFP para continuar con la tomadura de pelo actual cuando los servicios de esos generosos ministros y ex-ministros de la Concertación/Nueva Mayoría ya nos les sirvan?

En esa perspectiva, se entiende muy bien por qué para un número creciente de empresarios la alternativa Lagos (al margen de las mejores intenciones que pueda tener el candidato) aparece como la mejor (¿única?) forma de reconstruir el sistema de dominación y acumulación actual. Una alternativa que quizás podría volver a reagrupar a los agobiados, y a la cual los dueños del capital le podrían volver a delegar, y con tranquilidad, el manejo de las instituciones necesarias para implementar dicha dominación pues pueden confiar que ellos jamás se van a olvidar quienes son (sub-contratados), y de cual es su rol en el sistema.

Sin embargo, creo que esa ya es misión imposible. Desde mi perspectiva, de ganar Lagos la próxima elección, a pesar de sus formidables habilidades políticas, quizás no va a poder hacer más que dilatar una compleja pero imparable desarticulación de un sistema de dominación y acumulación que hace rato ya topó fondo - aquél que creaba consensos en torno a una ideología que se puede resumir en el lema: "Teme al $1 \%$, honra al mercado" (bueno, lo que en Chile llamamos eufemísticamente "mercado").

Creo que para lo que queda del orden actual el problema de fondo no es que haya quedado en evidencia que el rey no tenía ropa; el problema es que quedó en evidencia que el prócer de los renovados se viste con ropa ajena.

Por tanto, también sería realmente interesante conocer en forma más específica cómo nuestra elite capitalista visualiza un futuro que sea para ellos sustentable, pues este sistema de dominación hace aguas ya que cada día se hace más difícil mediatizarlo. No es muy difícil darse cuenta que los que están descontentos ya no quieren ser representados por sub-contratados; y es complicado que el gran 
capital, de querer continuar con su tajada del león, pueda dominar directamente en democracia. ¿Tendrán alguna idea de cómo salir del entuerto desde el punto de vista empresarial, fuera de continuar con la creciente fuga de capitales, aquello que se prefiere llamar inversión chilena en el extranjero?

Peor aún, ¿alguna idea, fuera de continuar endeudándose en el extranjero en dólares para luego sacarlos de Chile al resto de la región, en especial a países donde este sistema de dominación y acumulación tan primitivo parece tener todavía para rato? Como ellos sabe mejor que nadie, la deuda corporativa chilena en dólares ha sido la tercera que ha crecido más en el mundo emergente desde 2007 (después de China y Turquía) - alrededor del 20\% del PIB. ${ }^{16}$ Pero la inversión privada chilena está por el suelo. ¿Será que la solución para los problemas actuales de nuestro país, como parecen creer los del $1 \%$, es que los pasivos se queden aquí, pero los activos emerjan en otra parte donde supuestamente hay más "garantías"? Ellos lo llaman "internacionalización” de sus grupos, porque Chile le quedó chico. ${ }^{17}$ Para ellos (poco agradecidos) Chile ya no es un país tratando de transformarse en nación; parece que es sólo un mercado que les quedó chico para seguir haciendo las mismas cosas que han hecho siempre.

En un mundo globalizado, de existir un Estado con un mínimo de respeto de sí mismo, Chile podría ser una base ideal para un programa "asiático" de diversificación productiva, en especial basada en la industrialización del sector primario-exportador. Pero eso les exigiría harto más a los grupos económicos, y los premiaría con bastante menos. Pero entonces seríamos, y no sólo en el futbol, campeones de América.

José Ortega y Gasset nos decía que el principal problema de América Latina era que había demasiados individuos satisfechos consigo mismo y con demasiado narcisismo, pues les gustaba mirar la realidad como espejo de auto contemplación. Toda la razón: basta mirar nuestro 1\% y tanto político de la ex-Concertación. Para él ese era un gran obstáculo, pues faltaba descontento, motor del progreso. Yo generalizaría eso, pues no solo el descontento puede 
crear dinámicas transformadoras muy interesantes, sino también otros aspectos de aquello que es parte de esa tendencia natural (tanto en el mundo físico, como en el social) del orden en transformarse constantemente en desorden - y de subir su entropía. El descontento es un componente fundamental de eso en lo social, pero no lo único. $\mathrm{Y}$ es esa tendencia al desorden lo que genera los nuevos desafíos que requieren de una continua sofisticación de nuestras formas de dominación y acumulación.

De ser así, nuestro problema no puede ser más obvio: nuestra Latinoamérica neo-liberal - ¡y ciertamente la otra! - reprueba ese examen. Asia, en cambio, con sus errores, saca buena nota en todo esto. Y nuestra "nueva izquierda", por los fantasmas de su pasado (todavía persecutorios), por su tendencia intrínsecamente conservadora, por una no despreciable cuota de conflictos de interés (anzuelos que les tiró la oligarquía) - y por tanto consejero con poca "Imaginación (consultores)", en especial para el cambio - trata (y por un tiempo con mucho éxito) mas bien de contener ese nuevo desorden que de encausarlo hacia formas más sofisticadas de desarrollo. Creo que hay muchas similitudes en la falta de imaginación productiva de nuestros grandes empresarios (grandes en tamaño), y la falta de imaginación social de los renovados. Quizás por eso fueron, y por tanto tiempo, tan buena collera. ¡Pero ahora se le despabiló el novillo!

\section{Notas de PÁgina}

${ }^{1}$ http://ciperchile.cl/2016/09/26/un-par-de-preguntas-aandronico-luksic-el-hombre-publico/

${ }^{2}$ http://www.wid.world/\#Database:

${ }^{3}$ h t t p : / / a tabank.worldbank.org/data/reports. aspx? source=world-development-indicators.

${ }^{4}$ http://www.bloomberg.com/news/articles/2013-09-05/riskahoy-maersk-daewoo-build-the-worlds-biggest-boat.

${ }^{5} \mathrm{http}$ ///www.econ.cam.ac.uk/research/repec/cam/pdf/ cwpe1627.pdf. 
${ }^{6}$ http://stats.oecd.org/index.aspx?queryid=66670\#.

${ }^{7}$ http://ssrn.com/abstract=2479685.

${ }^{8} \mathrm{http}: / / \mathrm{www}$. econ.cam.ac.uk/research/repec/cam/pdf/ cwpe1539.pdf.

${ }^{9}$ https://www.youtube.com/watch?v=Riucws3AwDk.

${ }^{10}$ http://www.wid.world/.

${ }^{11} \mathrm{http}$ ///www.econ.cam.ac.uk/research/repec/cam/pdf/ cwpe0927.pdf.

${ }^{12} \mathrm{http}: / /$ elsa.berkeley.edu/users/saez/saez-UStopincomes-2012. pdf.

${ }^{13} \mathrm{http}$ //www.econ.cam.ac.uk/research/repec/cam/pdf/ cwpe1627.pdf.

${ }^{14}$ http://ciperchile.cl/2015/11/03/el-tpp-o-como-cedersoberania-por-secretaria/; y http://ciperchile.cl/2016/06/09/tppqepd/.

${ }^{15} \mathrm{https}: / / \mathrm{www} \cdot$ google.com/url? $\mathrm{sa}=\mathrm{t} \& \mathrm{rct}=\mathrm{j} \& \mathrm{q}=$ = $\mathrm{Lesrc}=\mathrm{s} \&$ source= web\&cd $=1 \& \mathrm{cad}=$ rja \&uact $=8 \&$ ved $=0 \mathrm{ahUKEwjwkIPYpZ3PAhUEI}$ JAKHcP1AYkQFggeMAA\&url=https $\% 3 A \% 2 F \% 2 F w e b . s t a n f o r d$. edu $\% 2$ Fgroup $\% 2$ Fmcnollgast $\% 2$ Fcgi-bin $\% 2$ Fwordpress $\% 2$ Fwpcontent $\% 2$ Fuploads $\% 2$ F2013\%2F10\%2FLimited_Access_ Orders_in_DW_-II_-2011.0125.submission-version.pdf\&usg=AF QjCNFvrw2eLZzIIirpcYeRAT_XK0Ijmw.

${ }^{16}$ http://www.econ.cam.ac.uk/research/repec/cam/pdf/ cwpe1539.pdf.

${ }^{17} \mathrm{http}: / /$ www.latercera.com/noticia/negocios/2016/09/655695208-9-luksic-el-tamano-que-tenemos-ya-es-importante-paraeste-pais.shtml.

Fecha de Recepción del Artículo: 20 de julio de 2016 Fecha de Aceptación: 14 de noviembre de 2016 